\title{
MULTI-PLATFORM SATELLITE BASED ESTIMATES OF RUNOFF IN UNGAUGED AREAS
}

\author{
Jae Young Seo ${ }^{\mathrm{a}}$ and Sang-Il Lee ${ }^{\mathrm{b}}$ \\ ${ }^{a}$ Dept. of Civil and Environmental Engineering, Dongguk University, Seoul, Republic of Korea \\ dabbi2011@naver.com \\ ${ }^{\mathrm{b}}$ Dept. of Civil and Environmental Engineering, Dongguk University, Seoul, Republic of Korea \\ islee@dongguk.edu
}

KEY WORDS: Ungauged area, Long-term runoff, Multi-platform satellite, GLDAS

\begin{abstract}
:
Over the past decades, extreme weather events such as floods and droughts have been on a steady increase. Especially, ungauged or hard-to-reach areas turn out to be the most affected areas by the unexpected water-related disasters. It is usually due to insufficient observation data, and deterioration of infra-structures as well as inadequate water management system. For such reasons, reliable estimation of runoff is important for the planning and the implementation of water projects in ungauged areas. North Korea, whose terrain is mostly hilly and mountainous, has become vulnerable to floods and droughts due to poor watershed management based on unreliable hydrological information along with rapid deforestation. Runoff estimation using data from multi-platform satellites having broad spatio-temporal coverage could be of a valuable substitute for ground-observed measurements. In this study, monthly runoff in North Korea $\left(38^{\circ} \mathrm{N}-43^{\circ} \mathrm{N}, 124^{\circ} \mathrm{E}-131^{\circ} \mathrm{E}\right)$ was estimated by combining space-borne data from multi-platform satellites with ground observations. Period of analysis is from January 2003 to December 2013. Data sets used for this study are as in the following: (1) Terrestrial Water Storage Anomaly (TWSA) from Gravity Recovery and Climate Experiment (GRACE), (2) Evapotranspiration from Moderate Resolution Imaging Spectroradiometer (MODIS), (3) Satellite-observed precipitation from Tropical Rainfall Measurement Mission (TRMM), and (4) Ground-observed precipitation from World Meterological Organization (WMO) (see Figure 1 and Table 1). These components are balanced with the terrestrial water storage change, and runoff can be estimated from eq. (1).
\end{abstract}

$$
R=P-E T-\frac{d s}{d t}
$$

where, $R=$ Runoff [cm/month], $P=$ Precipitation [cm/month], $E T=$ Evapotranspiration [cm/month], $\frac{d S}{d t}=$ Terrestrial water storage change $[\mathrm{cm} / \mathrm{month}], t=$ Time.

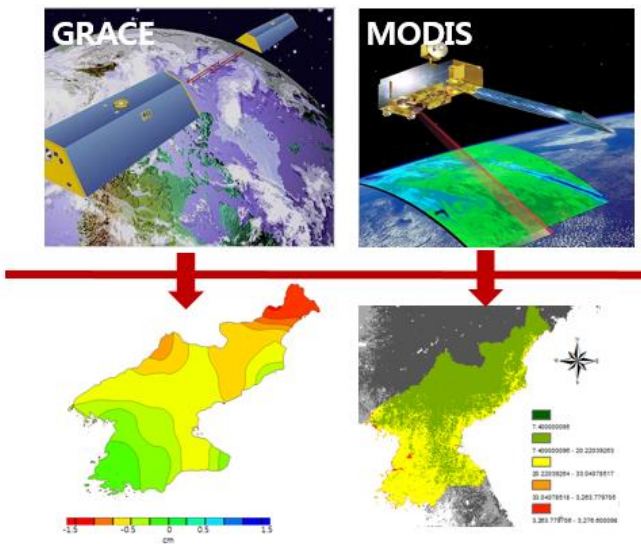

Terrestrial water storage Evapotranspiration

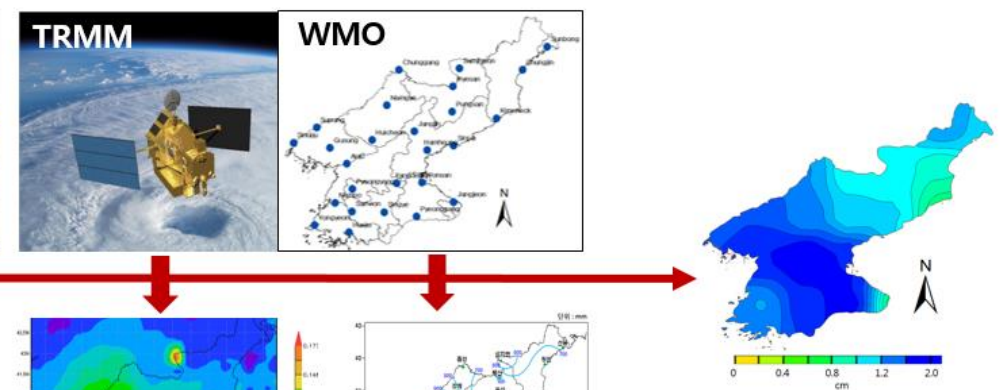

Total Runoff

Figure 1. Incorporation of Various Data for Runoff Estimation 
The International Archives of the Photogrammetry, Remote Sensing and Spatial Information Sciences, Volume XL-2/W4, 2015 Joint International Geoinformation Conference 2015, 28-30 October 2015, Kuala Lumpur, Malaysia

Table 1 Summary of datasets used for this study

\begin{tabular}{cccc}
\hline Dataset & Variable & Spatial Resolution & Temporal Resolution \\
\hline GRACE & TWSA & $1^{\circ} \times 1^{\circ}$ & \\
MODIS & Evapotranspiration & $1 \mathrm{~km} \times 1 \mathrm{~km}$ & Monthly \\
TRMM & Precipitation & $0.25^{\circ} \times 0.25^{\circ}$ & \\
GLDAS & Surface/Subsurface runoff & $1^{\circ} \times 1^{\circ}$ & \\
\hline
\end{tabular}

Upscaling methods were used to integrate the various spatial and temporal scales of each dataset (Hong, 2008). Estimated runoff time series during the study period were compared the results with those of four land surface models (CLM, Noah, Mosaic, and VIC) in GLDAS (Global Land Data Assimilation System; GES DISC, 2015). Results show a good agreement in seasonal pattern between two time series. It indicates that there is sufficient reliability in combining multi-platform satellite measurements with ground observation data. Currently, baseflow estimation is under way. By extracting the baseflow from total runoff, surface runoff which accounts for the flow regime in an area is expected to be obtained.

\section{ACKNOWLEDGEMENTS}

This research was supported by a grant (14AWMP-B079364-01) from Water Management Research Program funded by Ministry of Land, Infrastructure and Transport of Korean government.

\section{REFERENCES}

GES DISC, 2015. http://ldas.gsfc.nasa.gov/gldas

Hong, S. 2008. Mapping regional distributions of energy balance components using optical remotely sensed imagery. New Mexico Institute of Mining and Technology. New Mexico, USA. 